\title{
Prime Beef Cuts: Culinary Images for Thinking 'Men'
}

\author{
Douglas Brownlie \& Paul Hewer
}

The paper contributes to scholarship theorising the sociality of the brand in terms of subject positions it makes possible through drawing upon the generative context of circulating discourses, in this case of masculinity, cuisine and celebrity. Specifically, it discusses masculinity as a socially constructed gender practice (Bristor and Fischer, 1993), examining materialisations of such practice in the form of visualisations of social relations as resources for "thinking gender" or "doing gender". The transformative potential of the visualisations is illuminated by exploring the narrative content choreographed within a series of photographic images positioning the market appeal of a celebrity chef through the medium of a contemporary lifestyle cookery book. We consider how images of men "doing masculinity" are not only channelled into reproducing existing gender hierarchy and compulsory heterosexuality in the service of commercial ends, but also into disrupting such enduring stereotyping through subtle reframing. We acknowledge that masculinity is already inscribed within conventionalised representations of culinary culture. In this case we consider how traces of masculinity are exploited and reinscribed through contemporary images that generate resources for rethinking masculine roles and identities, especially when viewed through the lens of stereotypically feminised pursuits such as shopping, food preparation, cooking, and the communal intimacy of food sharing. We identify unsettling tensions within the compositions, arguing that they relate to discursive spaces between the gendered positions written into the images and the popular imagination they feed off. Set against landscapes of culinary culture, we argue that the images invoke a brand of naively roughish "laddishness" or "blokishness", rendering it in domesticated form not only as benign and containable, but fashionable, pliable and, importantly, desirable. We conclude that although the images draw on stereotypical premeditated notions of a feral, boisterous and untamed heterosexual masculinity, they also set in motion gender-blending narratives 
which test the shifting limits of masculine discourse when set in the mediating context of culinary culture.

Keywords: Visual Representation; Culinary Cultures; Cookbooks; Masculinities

\section{Introduction}

... every power which manages to impose meanings and to impose them as legitimate by concealing the power relations which are the basis of its force, adds its own specifically symbolic force to those power relations. (Bourdieu 1977, xv)

This paper is about the social meaning of things in their generative context-in this case the consumption practices that work to make an object (a celebrity brand) meaningful within webs of social relations and "flows of disjuncture and difference" (Lury 2004, 14). The subject positions which constitute the conditions of possibility of the brand are drawn from those webs and flows and the discursive spaces they open up. They not only make possible the renegotiation of the discursive architecture available within those spaces; they also construct relational intersections that put in motion subjectivities through "the heterogeneous distribution of meanings and the multiplicity of overlapping cultural groupings that exist within the broader sociohistoric frame of globalization and market capitalism" (Arnould and Thompson 2005, 869). The paper develops case material from an investigative site that consists of the branding of a celebity chef through a collection of superior photographic print images situated within a contemporary "lifestyle" cookery book. This text is one product within a range of related celebrity merchandise branded under the "Jamie Oliver" livery. ${ }^{1}$ In exploring the positioning of this text as a cultural artefact, we argue that our case illuminates some of the diverse and fluid ways in which male identity is shaped by cultural and economic forces, particularly how gendered representations function as a mode of economic production.

A close reading of the literature reveals that cookbooks, recipes and other representations of food have always worked with coded emancipatory intent (cf Brownlie, Hewer and Horne, 2005; Inness 2006; Wilk 2006). Indeed in his detailed study of the evolution of the culinary culture of the Caribbean, Wilk $(2006,61)$ observes the "heavy symbolic weight" of food and its representations in the slave economy of the nineteenth century. In this context he concludes that not only was food an important marker of ethnicity, but it functioned as a source of resistance to the oppression of the colonial plantation system of the time. Food and its coded representations then offered enslaved people access to a system of taste, choice and distinction which was a pivotal source of dignity and empowering activism. Cookbooks have always had a political agenda, in that women have used them over the years to protest or resist the oppressive social norms of patriarchal cultural structures, to subvert the phallocentric symbolic order, or if you like, to find moments when the "arbitrary assumptions" (Bristor and Fischer 1993, 522) of patriarchal structures become unstable. We note that cookbooks have also shamelessly exploited circulating gender stereotypes to construct subject positions that situate the market appeal of their content around the performance of 
traditional female roles, typically adorned with vivid visualisations of the ingredients, the preparation, the end products and sometimes the cooks.

What makes the present "Jamie Oliver" brand phenomenon of interest is not only that the subject text is true to the cookbook genre, in that it employs the over-determined codes of circulating gender stereotypes (of masculinity in this case) to situate its market appeal. But, moreover, it is playful with those stereotypes, nudging away at their assumed limits, subtly disrupting uncontested norms, bending them ever so gently to the imperatives of wider contemporary debates about dynamic gender relations and identities. And in offering resources to help undo, or at least resist embedded assumptions about socially acceptable forms of masculinity, we argue that the "Jamie Oliver" cookbook may also offer material that is suggestive of strategies for the transformative performance of gender relations. We find that the content of those strategies is generated by means of images informed by ideas that turn on the blurring of boundaries between manly conduct in work and leisure pursuits; between the public world of the workplace and the intimate, private world of domesticated culinary culture; and stereotypical male activities and subject positions often revealed through such epithets as "real men don't eat quiche". It is then possible to understand those images as sites for rethinking, not only how masculinity is performed, but also how we seek to fashion non-threatening representations of such conduct. Deeply rooted anxieties can surround the disruption of even apparently minor details defining masculine gender differentiation, especially fears of effeminacy and homosexuality, for as Chalmers argues "gender has the capacity to naturalize any differences it articulates" $(2001,21)$.

\section{The Brand as Media Object}

The paper explores how the "Jamie Oliver" brand can be understood not only as a form of commercial power, or a way of structuring competition in markets, but as a "media object" (Manovich 2001) which puts culture to the service of marketing ends. We argue that this perspective helps to open up arguments about how the market is organised and performed through circuits of commercial culture: in other words, how the market is enacted through circulating discourses that frame flows of information between producers and consumers of image instruments. In this way the brand can also be understood as a "medium of translation", an "interface" (Lury 2004, 6) by means of which cultural codes in circulation are organised recursively as a mode of production, built around sets of everyday conventions that articulate difference, so giving an object meaning within specific social relations.

The paper takes the photographic content of the cookbook as constructed spaces or environments with gendered characteristics. And within those built environments we argue that representations perform identity work as spatialised forms of discursive practice, allowing us to explore gender performance as the content of those images. It works on the images as available models for unpacking gender relations, framed by the narratives into which particular representations of gender identity have been inserted. The paper investigates the mediating role played by the cookbook as a cultural artefact, seeing it as a way of further distributing or circulating powerful gender codes in pursuit of 
commercial success. In the context of this study the paper understands gender as a symbolic form which is put to cultural work, appropriated towards the production of meaning within the landscaped environments of the images, and as Pettinger concludes: "[b] randing can thus be seen as a cultural tool used to enhance organizational economic performance" (2004, 180).

In arguing that we cannot apprehend the cultural work of images outside of the "gender, racial and ethnic frames by which they are articulated" (Butler 2004, 10), the paper focuses on how assumptions about gender are naturalised (Scott 2005), working through visual consumption practices in ways that are unspoken and invisible. Taking gender to be one site of visual consumption practice, the paper explores the social construction of masculinities, particularly circulating relations between marks of identity, in this case images with gendered content, and the "cultural institutions of marketing communication and market segmentation" (Schroeder and Zwick 2004, 21).

After Butler (1990) and Bristor and Fischer (1993) the paper argues that gender is a potent force within cultural frameworks that forge and preserve finely honed senses of social difference (Scott 2005, 13). It is one of the significant differentiating features which defines identity. Consumption is understood as a way of obtaining the cultural resources of everyday life from which social differentiation is constructed and gender identities forged and performed (Butler 1990, 139). In understanding those resources as the raw material from which culture constitutes and reproduces itself, the paper explores the generation of cultural meaning in marketplaces and how markets are discursively enacted by signifying practices, themselves situated within gendered frameworks of understanding.

We pursue the line of argument that ideas of gender identity do not possess a transcendental, unchanging quality, but are constituted in and through processes of their articulation and representation. Thus, the paper investigates how, in the context of communicating market appeals, socially produced assumptions about gender identity perform cultural work which functions as its own advertisement and in so doing, as Lury notes, "creates an audience for itself" $(1993,207)$. We argue that as two-dimensional simulacra, photographic representations of culinary culture not only make use of gendered signifiers, they instruct on gender roles, performing identity work for the brand through, as Schroeder and Zwick observe, "play[ing] a central role in forming conceptions of masculinity and help [ing] construct market segments" (2004, 22). In broad terms, the paper thus explores how brands work to characterise themselves in cultural terms by means of inscribed gender differentiation built, in this case, on socially engineered associations between representations of culinary lifestyle and consumable masculinities.

\section{Consumable Masculinities}

In this paper we seek to interrogate the dynamic relationship between visual culture and cultural notions of gender as performance (Butler 1990). The formal study of masculinity has subjected a variety of cultural forms to textual analysis, from films like Fight Club (Trotta 2004), to TV crime shows like The Bill (O'Sullivan and Sheridan 2005) to 
studying sport celebrities like David Beckham as potential sources of cultural change (Cashmore and Parker 2003). Within consumer research, studies of mountain men (Belk and Costa 1998), Star Trek fans (Kozinets 2001) and bikers (Schouten and McAlexander 1995) have all foregrounded the activities and antics of men doing manly things, often in male environments (Caru, Cova, and Tissier-Desbordes 2004); while an emergent stream of consumer research considers the social construction of masculinity, specifically, images of the male body within advertising (Benwell 2003; Crewe 2003; Schroeder and Borgerson 1998; Patterson and Elliott 2002; Rutherford 1988; Rutherford 1992; Cronin 1997; Ostberg and Borgerson 2004; Schroeder and Zwick 2004).

Our study draws inspiration from this body of work to illustrate a visual approach to gender analysis, focusing on the case of one cultural artefact, the "Jamie Oliver" brand, under the conditions of the rapid expansion of its audience over the last 5 years. Through a close examination of the visual narrative content of print images employed in one of the "Jamie Oliver" cookbooks, The Return of the Naked Chef (Oliver 2000), the paper opens up questions about the social and cultural basis for the generation and use of ideas about gender identity. Those images are understood as thoroughly composed cultural texts that generate information about the way gender is invoked in support of market appeal, drawing their imagery, as Schroeder and Zwick suggest, "primarily from the stereotyped iconography of masculinity and femininity" (2004, 22). At one level it is clear that not only have skilful representational practices been employed in choreographing the photographs, they are also at work in manipulating ideas of gender identity that constitute the content of the images. We argue that the photographs themselves represent particular investments in writing particular forms of masculinity into the visual narrations of the images.

We offer a critical visual analysis of a series of photographs of the celebrity chef and his friends and associates that decorate and punctuate the text. We ask what those images have to say about notions of men and masculinity and how they contest or confirm social stereotypes about gender roles and relations of power. After Schroeder and Borgerson (1998) and Schroeder and Zwick (2004) we understand those representations as visual narrations of masculinity capable of educating the viewer about conventional modes of conduct, gender interaction and sex roles. Our contribution to debates around changing notions of masculinities focuses on representations of men shopping for food, preparing food, cooking it, eating it and enjoying sharing the products of cooking in a variety of social contexts. We suggest that the images tap into circulating resources of culinary culture, especially ideas of culinary practices as taken for granted arenas for the performance of gender roles and identities. A close reading of those images seems especially salient since much culinary practice typically originates or revolves around that most gendered of domestic spaces, the kitchen (Freeman 2004).

\section{Exploring Masculinities}

Rutherford discusses the dialectical nature of masculinity, whereby it is "given meaning through its culturally constructed difference from femininity" $(1992,76)$. This point is discussed by Brittan (1989) when he argues that 
[g] ender is never simply an arrangement in which the roles of men and women are decided in a contingent and haphazard way. At any given moment, gender will reflect the material interests of those who have power and those who do not. Masculinity, therefore, does not exist in isolation from femininity-it will always be an expression of the current image that men have of themselves in relation to women. (Brittan 1989, 3)

One quality which masculinity has previously sought to appropriate is that of rationality. This can be traced to Weber's seminal "Protestant Work" ethic (1976), whereby the sphere of production over consumption is valorised, but also in the work of Seidler, who argues: "[i]n Western Europe since the period of the Enlightenment in the Seventeenth Century, men have assumed a strong connection between their rationality and their sense of masculine identity. They have learned to appropriate rationality as if it were an exclusive male quality denied to others, especially women" $(1987,62)$.

However, we are told that much has changed in recent years, especially with men's increasing participation in the sphere of consumption, for as Bocock writes: "[m]en have become as much a part of modern consumerism as women. Their construction of a sense of who they are is accomplished as much through style, clothing, body image and the right looks as is women's" (1993, 102). This is echoed in the work of Mort (1996), who, in an early article entitled "Boy's Own? Masculinity, Style and Popular Culture" (1988) suggests: "[y] oung men are being sold images which rupture traditional icons of masculinity. They are stimulated to look at themselves-and other men-as objects of consumer desire. They are getting pleasures previously branded as taboo or feminine" (Mort 1988, 194). This reconfiguring of masculinities is partly achieved through style magazines such as Arena and Face which sought to construct a space free of the trappings of femininity and domesticity, a space in which women appeared but in a limited fashion as mere "talent" to the male gaze. The suggestion that masculinity is being refashioned and re-presented is continued in the work of Crewe (2003), who focuses upon the shift from the "new man" to the "new lad" and the significant role played by the editors of men's lifestyle magazines such as Loaded and FHM in placing this in the popular imagination. In a similar vein, Patterson and Elliott (2002) map out the significance of such men's lifestyle magazines and how they manage to invert the male gaze.

Likewise, Dyer in the article "Don't Look Now" ([1983] 1989) investigates images of men from pin-ups in the magazine Oh Boy! to Michelangelo's Moses, tracing the characteristic ways in which masculinity is represented. Dyer argues that such images typically portray the male model as looking "either off or up" ([1983] 1989, 200) to counter the powerlessness which results from the passive position of being gazed upon, as he writes: "it remains the case that images of men must disavow this element of passivity if they are to be kept in line with dominant ideas of masculinity-as-activity" ([1983] $1989,202)$. Such an approach draws heavily upon the seminal work of Goffman (1979), who in Gender Advertisements suggests that advertisers draw upon the "same corpus of displays, the same ritual idiom, that is the resource of all of us who participate in social situations" $(1979,26)$, with the result that they "conventionalise our conventions, stylise what is already stylisation, make frivolous use of what is already something considerably cut off from contextual contours. Their hype is hyper-ritualisation" $(1979,84)$. For Goffman, photographs are analysed as enabling the researcher to understand the 
way gender is pictured, rather than performed $(1979,25)$. It is this perspective that this paper seeks to rethink, through its focus upon representations as performances.

From this position gender is something that is accomplished; it becomes in other words performed. In our view then, this is why it is so interesting to foreground everyday practices like cooking, sharing a snack, having friends round for drink, or shopping for food, to focus upon representations of such activities and how they provide images to "do gender with" or to think gender with. Here we draw inspiration from the work of Cronin (1997), who appears to recast Goffman's initial ideas, when she considers advertising images as exploring "how seeing something can be doing something, in terms of a performative process constituting the self and the other through discourses of transparency and their relation to legibility" (Cronin 1997, 85). Exposure to images is therefore not a passive relationship, rather the visual is retheorised as a site of production, an embodied process of "reflexively imagining the self and performatively producing the self in those visual moments of exposure". Cronin charts this process within advertising images by drawing on the work of Judith Butler (1990). Or as Buchbinder explains her contribution: "[f] or Butler, then, it is not so much that, as subjects we 'have' gender, as that as subjects we 'do' gender, through an array of signs and signs systems" (1998, 121-22). Our own contribution is to explore a turn to cookery books and their representations for insight and understanding on men and masculinity.

\section{Cookbooks as Gendered Artefacts}

The argument that there may be more to cookery books than simply food recipes has been made by many authors (cf Murcott 1984). Appadurai, for example, argues that "we need to view cookbooks in the contemporary world as revealing artifacts of culture in the making" $(1988,22)$. While Tobias considers that "[c] ookbooks contain not only recipes, but hidden clues and cultural assumptions about class, race, gender and ethnicity. They reflect many of the dramatic transformations that have come to define the boundaries of the modern public sphere" $(1998,3)$. In this paper, we foreground the "hidden clues" and "cultural assumptions" around gender as a form of performance which emerge from a reading of contemporary cookbooks.

To achieve this, we draw upon the work of Appadurai (1988), for whom the idea of framing culture as "text" offers one way forward for an adequate empirical study of culinary culture and its naturalised forms of representation in cuisine and commodity cookbooks. After Miller we argue that

\footnotetext{
goods [cookbooks] represent culture because they are an integral part of that process of objectification by which we create ourselves as an industrial society, our identities, our social affiliations, our lived everyday practices. The authenticity of artefacts as culture ... derives from their active participation in a process of social self-creation in which they are directly constitutive of our understanding of ourselves and others. (Miller 1987, 215)
}

Like others (cf. Cook and Crang 1996, 132) we follow Miller in understanding culture as "involving processes in which cultural life is objectified, in which objects are constructed as social forms, and hence in which cultural artefacts have to be understood in relation to their social and spatial contexts" (Miller 1987, 215). 
Such theorisations establishes our central point that, from an analytical perspective, commodity cookbooks must be understood, not merely as instrumental texts, conveying, by means of recipes, information about ingredients, their assembly, processing and presentation. Instead, as this paper will explore, they also offer access to what Appadurai terms "unusual cultural tales" $(1988,3)$ suggestive, we would argue, of who (wo)men are, where they have been and where they may be going. The next question, therefore, becomes how this may be achieved. Our own perspective suggests that such tales are often conveyed primarily through the visual- namely the photographic image. In this sense contemporary cookbooks are noted for their aesthetic and highly visual quality. It is therefore through a critical visual analysis (Schroeder 2006) of the images within such a text that our research unfolds.

\section{Culinary Cultures and Gender}

To say that cookbooks have always been about gender may be overstating the case. However, it foregrounds the important link between notions of gender and its articulation in the cultural text that is the cookbook. For example, Tobias (1998) analysed cookery books published in eighteenth-century America, concluding that they served to position women and define their role in society. This line of argument is continued through the work of Pilchner (1995) who analyses Mexican cookbooks. She argues that they served as sources of "cultural capital" for women in Latin American society, not only through circulating information about native ingredients and recipes, but through providing instructions regarding how to do gender roles and identity. In this way the texts were seen to distribute discipline regarding gender conduct and relations, in other words to generate resources to think about the conduct of conduct. Likewise, in her analysis of two black women's cookbooks, Zafar (1999) notes that cookbooks represent a space through which gendered cultural identity is "recreated". In this way she likens her analysis to that of an ethnographic journal, providing a "reading of what we eat, to understand how we construct a self around the axes of food" (Zafar 1999, 463). Zafar sums up the revelations of her analysis as placing

African-American cuisine in a political context, record[ing] a social history that must not be forgotten, and relat[ing] the lived experience of the writer and/or her family. Much more than grits and greens, the signifying dishes of the Dardens and Smart-Grosvenor provide us with a taste of where we've been, who we are, and where we should be going. (Zafar 1999, 464)

Zafar thus suggests that cookbooks represent or function as "recoveries" or "recastings" of the culture of African-American consumption, as signs of refusal and resistance and of forbidden identity.

This use of cookbooks as cultural artefacts can also be traced in the work of Novero (2000). Her analysis of cookbooks published in Weimar Germany, between the First and Second World Wars, reveals how they function to "reconcile nutritional and economic precepts with an ideology of taste and a modern lifestyle" (Novero 2000, 163). This is most evident where she reveals how the representations situate cooking as a technical skill, mediated by the rhetoric of instrumental rationality and efficiency. For instance, in 
her analysis of a cookbook by Kopp, entitled Bache nach Grundrezepten (Bake with Basic Recipes, 1933), Novero shows how its content, that is the recipes, are rendered as if they were "formulas that have been tested and perfected and that women can theoretically reproduce. Following the instructions should lead to the same results each time" (2000, 167). Cooking is thus framed as a form of rationalised work, a form of domestic labour in which pleasure is derived from "the satisfaction in accomplishing the tasks efficiently and in saving time and money. Even then, women are encouraged to make good use of the freedom they gain. The extra time and money should be used purposefully, not simply for pleasure" (Novero 2000, 164-65). The primary means through which this curtailing of cooking is achieved, we are told, is through the visual representation of the act itself. That is to say, over five hundred black and white photographs illustrating the "precise" stages of food preparation are provided for the reader to emulate.

Warde (1994) provides a study of the changing contents of food columns in popular UK women's magazines between 1967 and 1992. Despite the disparity in decades studied he arrives at similar conclusions to those of Novero (2000), insomuch as he observes what he terms a discourse of compliance, noting that:

[i]nformation is now given fairly routinely, not only about precise quantities of ingredients and cooking times, but also about preparation time, nutrient contents, sometimes shopping instructions too ... science, measurement, the use of information derived from experiment, rather than trial and error and ad hoc judgement, appear more frequently in the food columns. (Warde 1994, 24)

This discourse of compliance contrasts with the notion of culinary practice as a potential site of gender resistance (Neuhaus 1999). Neuhaus analyses a cookbook by Peg Bracken entitled The I Hate to Cook Book (1960) as indicative of the social tensions of the late 1950s. It provides tales of the drudgery of cooking and the repression of women within a male dominated society, as she suggests: “a woman's work was never done. Even after a woman obtained a husband, her culinary skills remained a critical part of her attractiveness. Keeping a husband, in many of these texts, was often a matter of providing a good meal or having the perfect drink ready when he came home from work" (Neuhaus 1999, 538). In coded form the tacit message of the book suggests how women might avoid this drudgery through using processed foods and avoiding elaborate recipes, yet still be seen to fulfil the expectations of their defined role. This text functions in a subversive and liberating way-a counter-discourse-to clearly contest and encourage forms of everyday resistance to the dominant gender norms of the 1950s. As Neuhaus continues,

[c] ookbooks, in their efforts to seal up the growing cracks in gender ideology, actually left traces and clues about just where the cracks had begun to show. The dominant discourse that positioned cooking and food preparation as a natural, deeply fulfilling activity for all women spoke of the possibility that perhaps it was not. These texts articulated what must not be articulated but assumed, in order to maintain 'traditional' gender roles. (Neuhaus 1999, 547)

In this section we have outlined a range of insightful studies which have demonstrated the value of an approach which takes cookbooks seriously. Many studies foreground notions of femininity over masculinity, revealing such cultural texts as forms of "cultural capital" for women, but also as cultural landscapes where struggles over the meaning 
and performance of gender identities are played out. The early work of Miller (1988, 360 ) on council estate kitchens revealed how the social space of the kitchen tends to be perceived as a gendered space, a feminine domain, with men more reluctant to initiate changes to the look and appearance of this room, rather it is women who take on the role of creative appropriators. A finding echoed in the later work of Freeman (2004), who presents a cultural history of the making of the modern kitchen highlighting the significant part that women play in shaping the design of the kitchen space.

When it comes to cooking itself then, many studies have highlighted the gendered nature of this everyday act. Early feminist work was the first to highlight the fact that cooking tends to be perceived as "women's work" (Oakley 1974; Charles and Kerr 1987). While early work within the sociology of food illustrated the gendered nature of this act, best summed up in the words of one of Murcott's respondents (1983) "It's a pleasure to cook for him" (1983). In this way, cookbooks are about more than simply food preparation, presentation and consumption, rather cookbooks can also be seen to function as coded instructions regarding acceptable forms of performing gender identity through culinary practices. Cookbooks are thus revealing on the conduct of conduct, expressing ways of conducting an activity which on casual inspection has little to do with gender, but is in fact ridden with the expression of changing notions of gender. It is toward an understanding of the imagery of masculinity within contemporary cookbooks that the analysis turns.

\section{Gender and Critical Visual Analysis}

In terms of methods our paper is inspired by those studies which have foregrounded critical visual analysis as a valuable tool for consumer researchers (Schroeder 2006). Here we draw attention to the especially insightful work of Scott (1994), Stern and Schroeder (1994), Schroeder and Borgerson (1998) and Schroeder and Zwick (2004) which provide an in-depth analysis of a limited (typically three to four) range of advertising images. The seminal work of Goffman, Gender Advertisements (1979), is also used for inspiration. Schroeder and Borgerson (1998) outline the various forms of analysis available to the consumer researcher when faced with visual data. These range from formal content analysis to studies which prioritise interpretation and understanding. Our analysis seeks to unpack photographic images of culinary culture as a way of generating insights, not only about representational practices surrounding visual culture, but also about the visuality of contemporary consumption and masculinity (Schroeder 2002). After Wright (2004), we understand the photographic image as a medium and a site of material culture with the ability to achieve in its immanence an intense presence. The photographic image thereby becomes a site of representational practice, a site of signifying activity; where photographs can themselves be seen as social agents doing the work of larger cultural forces, where images are required to be that which they are used to signify. For as Scott explains: "we must learn to understand cameras not as machines that record the world as it is (or even as we see it) but as machines designed to represent the world in the manner we have learned to show it" $(1994,261)$. In this sense signification can be seen as a constitutive feature of the context of the communication that is 
taking place around the discursive subject of cooking, eating and sociability. From this analysis, several core themes have emerged, the main one being the notion of cooking and sociability as gendered spaces; the second, focusing upon the performance of masculinities, framed within the context of culinary culture.

\section{Masculinity with a Twist}

Buchbinder argues that it is the job of representation to "make what is represented seem, to the viewer, reader or onlooker, as large as life, and twice as natural" $(1998,1)$. We might add that it is also the task of representation to appear as if beyond explanation and critique. Representations in this sense appear all too natural, as if capturing the real rather than framing possibilities and expectancies. Many of the compositions within the book work hard to convey the pleasures to be had from the sociability that surrounds consuming and preparing food, or as he prefers "tucking in" (see Figure $1^{2}$ ). Within the text it is interesting that this is one of only two images which contain women, and in this case it is of a headless woman whose body is literally sliced up, a photographic device which Schroeder and Borgerson describe as committing acts of "symbolic violence [against women] by erasure of identity and intelligence" $(1998,178)$. The visual content of the remainder of the representations is male-dominated, providing images of Jamie shopping or preparing food alone; or anticipating the fun to be had sharing good food with others; or Jamie working with Genaro, the master chef (see Figure 4); or Jamie eating and drinking with his male friends (see Figures 2 and 3). And although the images work hard to frame male sociality in ways that erase traces of homophobic anxiety, the paradox of representation is, as keenly observed by Hall when commenting on the work of Foucault, that "[the viewer] must locate themselves in the position from which the discourse makes most sense, and thus become its 'subjects' by 'subjecting' themselves to its meanings, power and regulation. All discourses, then, construct subject-positions, from which alone they make sense" $(1997,56)$. So, by locating themselves in the differentiated subject positions incorporated into a particular discourse of masculinity and by investing their subjectivity in the identifications it offers, viewers are subject to both the creative possibilities and the constraining effects that inhere in those discourses (Chalmers 2001). Masculinity by this reckoning is clearly in the eye of the beholder.

Central to many of these images, as we shall see, is the notion of food as a facilitator of social communication with other men (see Figures 2 and 3). In this respect several images are presented of Jamie eating in communion with others. We argue that what is revealing about such images are the conventional representations of male sociality, which appear to hark back to traditional workplace-related notions of masculinity. For example, the section titled "Morning Glory"3 which covers breakfasts is preceded by an image of Jamie and buddy Ben literally "tucking into" what Jamie calls his "bacon sarnie my stylie".

The casually dressed figures are pictured sitting closely, elbows touching, on the kitchen floor, their backs resting against the doors of rather jaded and elderly kitchen units, consuming what can only be described as an over-sized bacon sandwich, a bottle of spicy HP sauce uncapped beside them, their plates resting on their legs decorated with 


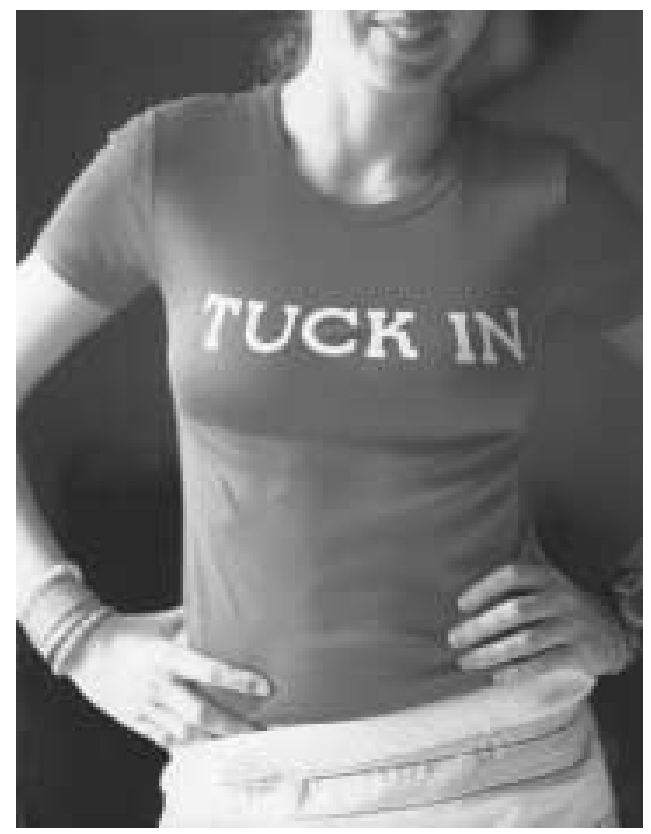

Figure 1 Tuck in. (Reproduced with the permission of photographer, David Loftus). Copyright (C) David Loftus.

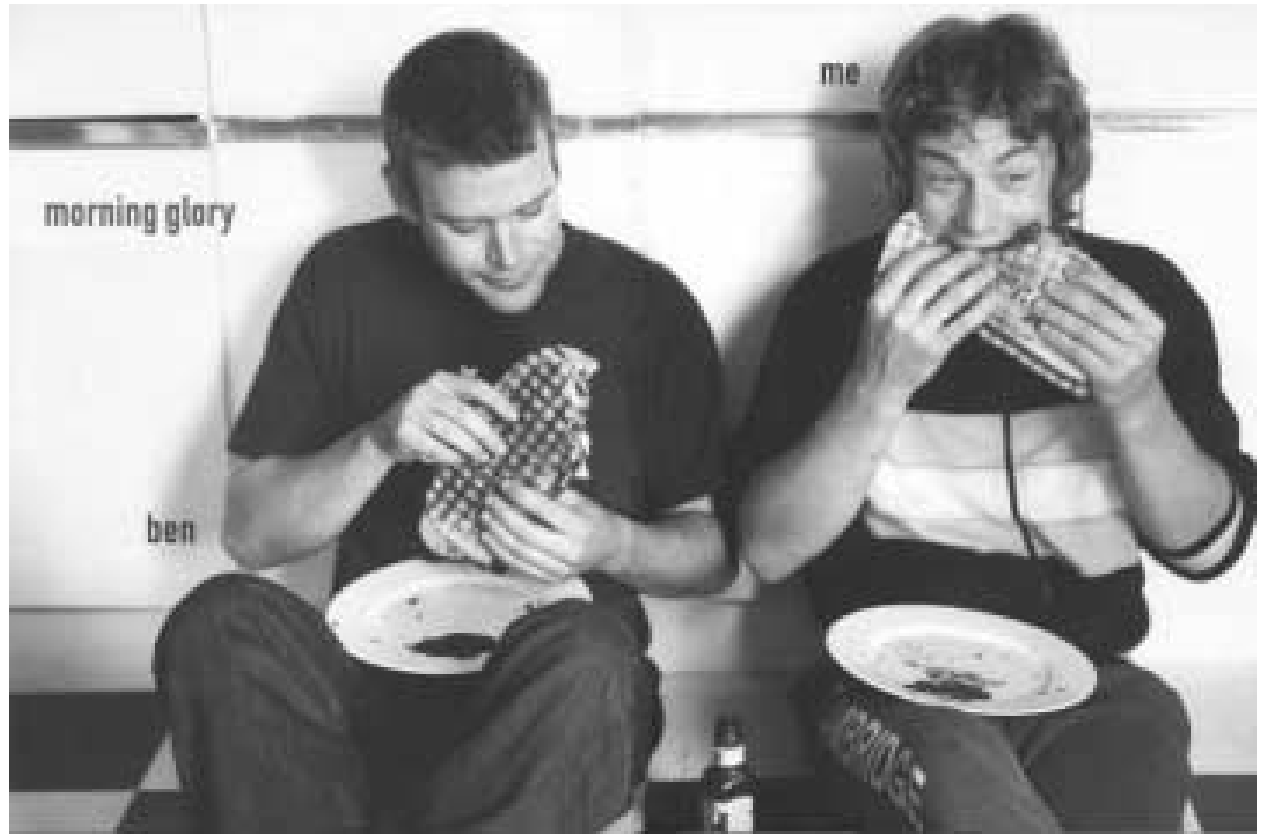

Figure 2 Men at work/play. (Reproduced with the permission of photographer, David Loftus). Copyright (c) David Loftus. 
a clot of sauce. In another context this could easily be a pair of scruffily dressed plumbers, electricians or joiners enjoying a well-earned break from the labour of typical male work within the kitchen-decorating, plumbing, construction, wiring, joinery etc. In such a scene, or enclave of masculinity as Caru, Cova, and Tissier-Desbordes (2004) have it, gender would typically be written into the image in ways that played on traditional productivist notions of male work and working relations in the workplace. But, the image of Ben and Jamie remains ambiguous in that the visual narrative is silent on what brings them to be sitting side by side on the kitchen floor eating. In leaving this up to the viewer's imagination, the image appears to draw on shifting discourses of work as a defining feature of male identity which dissolve and recast boundaries between work and leisure, between the work and the workplaces and spaces of men and women.

In this way the content of Figure 2 is said not simply about two men eating breakfast with their hands while sitting on the kitchen floor. It is an image about embodied male informality in terms of the figures striking manly poses and postures. It is also about two dependent men being men and interacting on the kitchen floor, whilst doing so without the protection or assistance of napkins, cutlery, table or chairs. It is an image which seeks to make possible and presentable the rhetorical claim that the kitchen is indeed a gendered domain —or, at least, that men feel excluded from it unless that is they are chefs (see Figure 4) - in order that it can also be said that it may be necessary to reclaim this space, to render it inclusive, for the performance of new forms of masculine communion, dependency and intimacy. In this manner the kitchen and its traditional associations with domesticity, sociability, nurturing, nourishment and motherhood is visualised as somewhere masculine men can be at ease, in much the same way as they might be on, say, a building site tucking into the contents of their lunch box or take-away from the local cafe. The image works hard then to jettison notions of the kitchen sink as being something that men and women only ever get chained to. For some women the kitchen is a lonely place and they may feel there to be plenty of space in it for a male of their choice to learn about how to do TLC. The image is then about men magically transforming and appropriating the domestic space, forging from it, to paraphrase Virginia Wolf, a room of their own, essentially through the performance of a male style of intimacy involving eating with a mate on the kitchen floor. Tensions emerge here depending on how you choose to fill in the blanks regarding the wider circumstances of the image. Invoking the framing stereotype of "blokes at work" plays off traditional characterisations of masculine identity through physical work and acceptable intimacy as camaraderie in the workplace. And this is helped by the focal point of the image being found at the depth of field where the subjects' hands are carefully wrapped around the sandwich, as if it were a fragile wind instrument. This effectively reduces the clarity of the faces, bodies, floor tiles and kitchen units which make up the backdrop of the image.

Competing versions of masculinity are revealed through framing the kitchen as a space which disrupts conventions regarding the characterisation of gender identity through work activity. By employing the kitchen as a transformative landscape against which to frame versions of male intimacy we can see how blurring the boundaries between the characterisation of work and leisure also destabilises gender stereotypes. Acceptable though some forms of male dependency and intimacy in the workplace may 
be, when work becomes leisure and the workplace becomes the kitchen, new and potentially disruptive versions of male intimacy emerge within the arena of culinary culture. As orchestrated dramas, the prints may draw on clear cultural categories to depict gendered selves. But, the unfinished nature of the visual narrative leaves room for the viewer to insert and improvise competing versions of gender identity. Styles of being male therefore become realised psychoanalytically through what Angel and Sofia (1996) term a "specular aesthetics of orality" in the performance of masculine identities organised around relationships "between seeing, desire, eating and consumption ... where overtones of devouring and eating are explicitly linked to the pleasurable consumption of commodities and images" $(1996,472)$.

The critical importance of "styles of being" (Butler 1990, 139) is similarly visualised in the section of the text entitled "Bevvies". This is preceded by an image of Jamie and two friends, Peter and Ben, consuming slices of watermelon flesh that have been marinated in vodka over a few days, hence the laddish signifier "bevvies". The lads are pictured jauntily riding bareback the shoulder of a well-worn leather sofa (see Figure 3).

Once again the key message is one of simultaneously widening and perpetuating the repertoire of stages and plots for the performance of male dependency and intimacy. In the previous case we examined the kitchen space as a framing device which has the potential not only to exploit but to disrupt gender stereotypes. In Figure 3 we are presented with a colourful image of three boisterous and virile young men at play within the constrained space of a leather sofa which effectively frames the print. In one way the image can be read as a story about mates having a lark, a bit of a laugh, perhaps

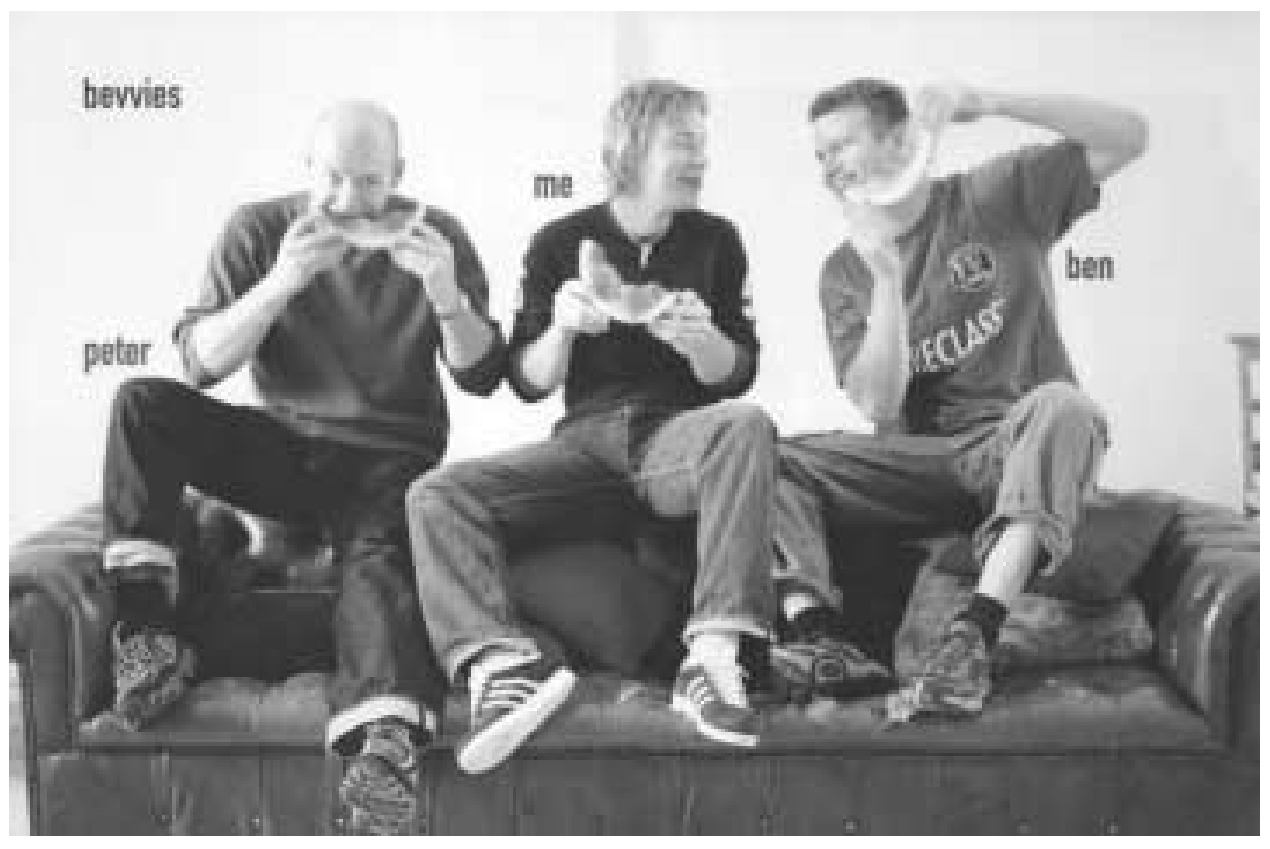

Figure 3 Bevvies. (Reproduced with the permission of photographer, David Loftus). Copyright $\odot$ David Loftus. 
while watching the football or a film, while the wife or partner is out shopping or away with the baby at her mother's. It conveys the unsettling idea that it can be fun to put a bit more effort or thought into your relationships-well, in this case, enough thought to be able to prepare an unusual cocktail to entertain your mates with. So this can be seen as an image of blokes living out a particular version of masculinity, of doing laddish things; of men performing their laddishness with some bravado in a mildly energetic way. And maybe some women like to think of men as being able and willing to put more effort and thought into their relationships; that they are able and willing to think and act on the idea of the point of food being, not merely to satisfy physiological appetites, but to enrich social relations. For example, note the homoerotic choreography of the image: Jamie perched in the middle; bodies draped in casual clothing; knees and elbows touching; focal distance around the turn-ups of the trousers and trainers at the edge of the sofa; backdrop starts at the knees; upper body and faces slightly out of focus; sleeves rolled up; Jamie and Ben smiling at each other and making eye contact; Peter looking at the gaze of the viewer; postures relaxed and open; posing on the shoulder of the sofa. Those components are manipulated to give the image a sense of movement and fun, hedonism and informality conveyed through the figures' demeanour, pose and appearance. The men with their sleeves rolled up, their legs splayed and outstretched, with their jeans rolled up, and doing that most taboo of acts in every (working class) parlour, resting your shoes on the furniture (albeit a torn and worn sofa). There is a fundamental symmetry to the image, conveyed through the mirroring of their space-consuming sitting positions, arms and knees swinging and dancing in unison, and eye contact which speaks of social affiliation. A sense of connection and communion is conveyed through the eye contact between Jamie and Ben, while Peter's direct gaze at the camera (the watch-wearer) seems to speak of distrust and intrusion - perhaps when the producer intends him to look as if he's watching TV. On male eye-contact, a quote from Henley's Body Politics (1986) appears apt here:

Eye engagement is like touch in its mystic and magnetic qualities. As in touch, a spark seems to pass between two persons whose eyes meet-sometimes a spark of recognition, sometimes one of love, sometimes one of conflict ... We look to the eyes for meaning. (Henley 1986, 151)

What we take from such images is a sense of the potential links to be forged between food shopping, preparation and consumption, and masculine identity. In other words, although our representations of those activities may be exploiting circulating ideas about new arenas for the performance of new forms of male identity, the images are not in themselves tools for rewriting ways of doing intimacy between men. Rather they instigate contemporary notions of masculinity already circulating among the popular imagination and set them to work, or unsettle them within the context of intersections with the iconography and symbolic structuring of culinary culture. We argue that the images may thus be seen as sites of identity formation, which work to simultaneously reinforce and conceal traditional notions of masculine sociability. The crudely traditional plot of this image and its easy tendency to perpetuate powerful gender stereotypes reveals to us that in working this way, the visual narrative also invites disruptive readings of the gender 
codes circulating in commercial culture. In this case we can understand this image of male sociability as a carefully contained display of playful homoeroticism, framed as riding the tail of the sofa bareback. The visual narrative of Figure 3 suggests that blokes can still be blokes and have "normal" manly fun eating cocktails in privacy, even if they won't be seen buying them to drink in the pub when out with their mates. And to this extent the image reproduces the excesses of the banal social stereotype that is lad or bloke culture, it therefore works to repress suggestions of competing versions of male intimacy and sociability that would make possible a more diverse set of masculinities.

\section{Masculinity Cooked}

The central argument of this paper is that notions of gender and masculinity are performed through everyday practices such as shopping, cooking, eating and socialising. In this respect, our interest lies in analysing those instances within the text where glimpses into the how of cooking are revealed. One such image frames cooking in a very specific way (see Figure 4). Here we are presented with a scene that is meaningful, which as Goffman might assert, "can be read in a flash" $(1979,27)$. In the image the two male chefs are shown in the act of preparing food, in this case fresh pasta. The composition presents an image of male intimacy in the context of a master-apprentice relationship, where pose, posture, dress and gesture work to suggest movement, understanding and display. The content of this image is not about men consuming food, as in the earlier pictures discussed. Rather it is an image of the representation of cooking as production and reproduction through cultural transmission. In an image of professional affiliation, the two men's elbows, shoulders and backs are seen touching as Genaro (the master) makes a particularly fine gesture of emphasis to Jamie (the apprentice), who looks fondly at Genaro smiling. The two men are pictured making pasta in the workplace, their kitchen. This is an image in which the spatial proximity of the two men is significant. Their communion is reinforced by the eye-contact between the two, where Jamie is shown gazing at the master, while Genaro's eyes are shown looking off. Finally Genaro is captured making a flamboyant aesthetic gesture with his right forefinger, which is arresting the attention of Jamie. There is a subtle symmetry at work in the image as the two chefs appear to be comfortable in each other's company.

A number of other images frame cooking in a very different style. One such revealing image pictures Jamie kneading some dough (see Figure 5). What is striking about the image is the sense of power and control conveyed through his shaping and moulding of the dough. One hand is pictured grasping the object, while the other hand is shown moulding this object, his fingers literally piercing the dough. His hands are thus captured in motion (note the blurring of the image of his right thumb), a visual representation of everyday agency which takes on the appearance of a performance. Like the previous photographs (see Figures 3 and 4 ) there is a dynamism here, expressing the ability of photography to capture the momentary and ephemeral performance of cooking. Meanwhile his eyes, semi-shut are fixed on the object at hand.

This is an image of the cook as a man-of-action (Holt and Thompson 2004), an image where the bond is not a social one, with other men, but with one's own labour. 


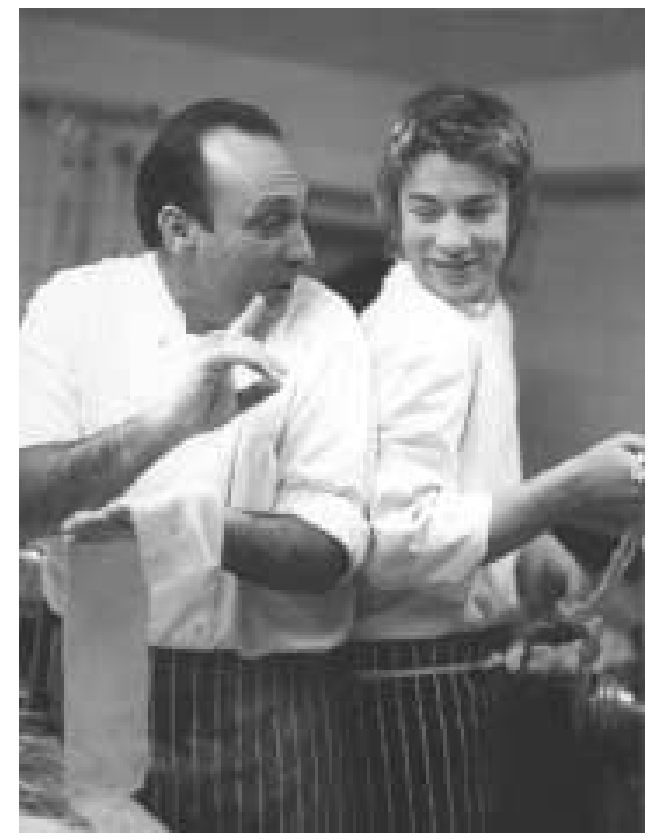

Figure 4 Man and boy. (Reproduced with the permission of photographer, David Loftus). Copyright (c) David Loftus.

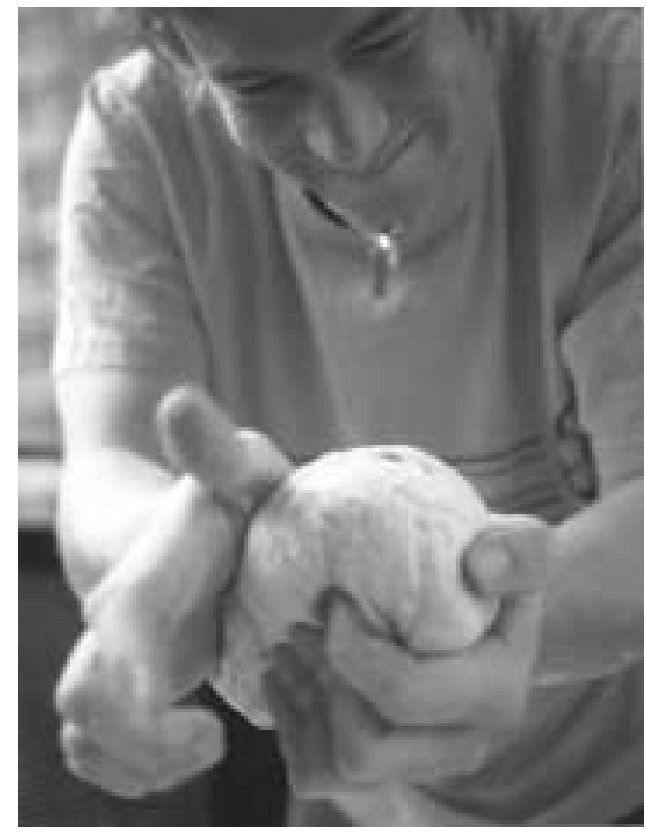

Figure 5 Man-of-action. (Reproduced with the permission of photographer, David Loftus). Copyright (C David Loftus. 
The link to what some might perceive as "manly Marxism", or more specifically Marx on estranged labour, is all-too-tempting to avoid, so a quote from the Economic and Philosophic Manuscripts of 1844 seems apt:

[i]t is clear that the more the worker spends himself, the more powerful becomes the alien world of objects which he creates over and against himself ... The worker puts his life into the object; but now his life no longer belongs to him but to the object. Hence, the greater this activity, the more the worker lacks objects. Whatever the product of his labour is, he is not. Therefore the greater this product, the less is he himself. (Marx 1981, 63)

Cooking in this sense is very serious stuff, a counter to the alienation of the world of work, but also it is very much represented to us as man's work, and there is a definite style and character to this man's way of doing cooking, in this case gently kneading the dough with care and control. Representations of cooking, especially when they depict cooking thus as a form of practice De Certeau et al 1998 become akin to a cultural praxis, or as Bauman might suggest: " $\mathrm{t}$ ] he separation of creation and control-the pith and marrow of alienation-lies at the basis of the reality of the society and its mental image. The act of creation is the only way open to man to control his existencein-the-world, to wit, to accomplish the double-pronged process of assimilation and accommodation" (1999, 127). What we might term the sexual politics of domestic representation here becomes apparent, especially when cooking is represented as an activity where the emphasis is placed upon reiterating those most masculine of appropriations: strength, power and control. This image of masculinity-in-the-world of representation contrasts with an image of Jamie making pasta (see Figure 6). Here the image of preparation is one of artful sculpting and detail, of careful moulding and shaping small ravioli parcels; images of strength are juxtaposed to those which focus upon the art and craft of cooking. This sense of the embodied nature of culinary culture is conveyed by the deliberate use of black-and-white, but also the close-up and cropped images of the dexterity of the fingers themselves.

There is almost a nurturing and maternal quality to the image on the top left-hand corner, where the hand is shown cupping the pasta in a very delicate manner. The photographs also depict the transition of the object to finished object through the process of cooking.

\section{Discussion}

Our task in this paper was a modest one, to analyse the representations in a contemporary cookbook which represent men doing the cooking. From this initial starting point we argued that such textual material offered to consumer researchers a rich set of data to pose the question of what they may be saying about men and masculinity. We show that in being playful with currently circulating notions of conventional masculinity, the images can stoke the anxieties of men who strongly align themselves with traditional gender hierarchies. In coming to this view, we suggest that the market appeal of the 'Jamie Oliver' brand is highly feminised. To conclude, it is useful to draw together some of the main insights to stem from an analysis of such representations. Firstly, the images suggest a story about men in the domestic space of the kitchen, a tale of how such a space 


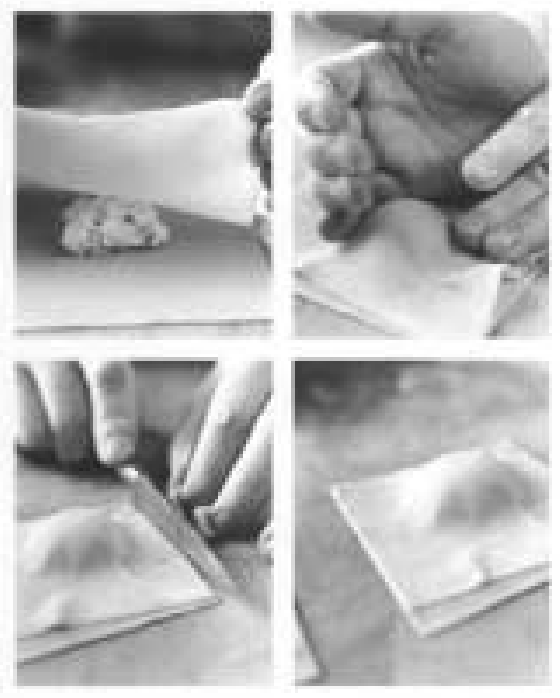

Figure 6 Man-ual dexterity. (Reproduced with the permission of photographer, David Loftus). Copyright (C) David Loftus.

can be appropriated in very masculine styles. Style thereby is critical and all-important and the images work to affirm a very masculine style of cooking, where the emphasis is upon safeguarding and protecting those most cherished of masculine traits. In addition, the images appear to say a lot about reconfiguring notions of male bonding and community within the domestic context. It is at this point that our modest ambition becomes somewhat bolder for our approach to representations and images, concurs with that of Miller on material culture, that is to say " $\mathrm{t}$ ] he less we are aware of them [i.e. representations], the more powerfully they can determine our expectations by setting the scene and ensuring normative behaviour, without being open to challenge. They determine what takes place to the extent that we are unconscious of their capacity to do so" (2005, 5). In this way, cookbooks must be understood as reflexive objects (Lash and Urry 2002), especially when they deal with images of men as we have attempted to show in this paper, but also when they picture women (Brownlie, Hewer, and Horne 2005; Hewer and Brownlie 2005), part and parcel of visual and material cultures. By this reckoning, images must be taken seriously for their ability to delight, but also, as Miller argues, since they serve also to "habituate and prompt us" into accepting particular versions of social reality; or as we prefer, cooking up prime cuts of masculinity within a postmodern world where recipes for consuming have become all-important.

\section{Acknowledgements}

In writing this paper we acknowledge the support and insights provided by the anonymous reviewers. But more so we acknowledge the cooperation of David Loftus the 
photographer who took these photographs of Jamie Oliver and who kindly allowed us to reproduce them for the purposes of our research.

\section{Notes}

[1] At the time of writing, the range of merchandise branded under the Jamie Oliver Ltd. label is available worldwide. It is produced in the UK and includes nine authored cookbooks, a biography, numerous introductions to cookbooks authored by others, posters, calendars, DVDs, CDs of music to cook by, pan sets, flavour shakers, pot roasts, pressure cookers, pot roasts, slow cookers, pannini and fajita grill pans, toss and turn tongs, woks, frying pans, lasagne dishes, ragout pans, risotto pots, pasta pots, omelette pans and milk pans. The study discussed in this paper is based on an analysis of visual images contained in the Jamie Oliver cookery book The Return of the Naked Chef (Oliver 2000). A visit to the Amazon website shows that the Jamie Oliver brand, while born in the UK, attracts a wide and avid fanbase from around the world.

[2] Please note that originally photographs reproduced here as Figures 1, 3 and 5 were published in colour. However, due to copyright restrictions they are reproduced in black and white. If you wish to view the colour versions please refer to Oliver (2000).

[3] For music fans, this might refer to the Oasis album "What's the Story Morning Glory", for the green-fingered amongst you this might signify a genus of mainly evergreen shrubs otherwise known as ipomoea purpurea; and for the phallic-minded reader, Green (2000) suggests that morning glory refers to "sexual intercourse before one gets up in the morning".

\section{References}

Angel, M., and Z. Sofia. 1996. Cooking up: Intestinal economies and the aesthetics of specular orality. Cultural Studies 10 (3): 464-82.

Appadurai, A. 1988. How to make a national cuisine: Cookbooks in contemporary India. Comparative Studies in Society and History 30 (1): 3-24.

Arena

Arnould, E., and C. Thompson 2005. Consumer Culture Theory (CCT): Twenty Years of Research. Journal of Consumer Research 31 (March): 868-882.

Bauman, Z. 1999. Culture as praxis. London: Sage.

Belk, R. W., and J. Costa. 1998. The mountain man myth: A contemporary consuming fantasy. Journal of Consumer Research 25 (3): 218-40.

Benwell, B. 2003. Masculinity and men's lifestyle magazines. Oxford: Blackwell.

The Bill. n.d. Television series. UK.

Bocock, R. 1993. Consumption. London: Routledge.

Bourdieu, P. 1977. Reproduction in education, society and culture. London: Sage.

Bracken, P. 1960. The I hate to cook book. New York: Harcourt Brace.

Bristor, J., and E. Fischer. 1993. Feminist thought: Implications for consumer research. Journal of Consumer Research 19 (March): 518-36.

Brittan, A. 1989. Masculinity and power. Oxford: Basil Blackwell.

Brownlie, D., P. Hewer, and S. Horne. 2005. Culinary tourism: An exploratory reading of contemporary representations of cooking. Consumption, Markets and Culture 8 (1): 7-26.

Buchbinder, D. 1998. Performance anxieties: Re-producing masculinity. St Leonards, NSW, Australia: Allen \& Unwin.

Butler, J. 1990. Gender trouble: Feminism and the subversion of identity. London: Routledge. 2004. Undoing gender. London: Routledge.

Caru, A., B. Cova, and E. Tissier-Desbordes. 2004. Consumerscapes as enclaves of masculinity. Proceedings of the 7th ACR conference on Gender, Marketing and Consumer Behavior, Madison, Wisconsin. 
Cashmore, E., and A. Parker. 2003. One David Beckham? Celebrity, masculinity, and the soccerati. Sociology of Sport 20 (3): 214-31.

Chalmers, L. V. 2001. Marketing masculinities: Gender and management politics in marketing work. Westport: Greenwood Press.

Charles, N., and M. Kerr. 1987. Women, food and families. Manchester: Manchester University Press.

Cook, I., and P. Crang. 1996. The world on a plate: Culinary culture, displacement and geographical knowledge. Journal of Material Culture 1 (2): 131-53.

Crewe, B. 2003. Representing men: Cultural production and producers in the men's magazine market. Oxford: Berg.

Cronin, A. M. 1997. Temporalities of the visual and spaces of knowledge: Branding the "third dimension" in advertising. Space and Culture 1 (1): 85-104.

De Certeau, M., L. Giard, and P. Mayol. 1998. The practice of everyday life, volume 2: Living and cooking. Minneapolis: University of Minnesota Press.

Dyer, R. [1983] 1989. Don't look now. In Zoot suits and second-hand dresses: An anthology of fashion and music, edited by Angela McRobbie. Basingstoke, Hampshire: Macmillan, 198-207.

Face. n.d. UK.

FHM. n.d.

Fight Club. 1999. Film. Directed by David Fincher, distributed by 20th Century Fox, USA.

Freeman, J. 2004. The making of the modern kitchen. Oxford: Berg.

Goffman, E. 1979. Gender advertisements. London: Macmillan Press Ltd.

Green, J. 2000. Dictionary of slang. London: Cassell \& Co.

Hall, S. 1997. Representation: Cultural representations and signifying practices. London: Sage.

Henley, N. M. 1986. Body politics: Power, sex and nonverbal communication. New York: Simon \& Schuster, Inc.

Hewer, P., and D. Brownlie. 2005. Re-enchantment and the kitchen: Exploring the visual grammar of culinary cultures. Copenhagen workshop on Interpretive Consumer Research, May 2005.

Holt, D. B., and C. J. Thompson. 2004. Man-of-action heroes: The pursuit of heroic masculinity in everyday consumption. Journal of Consumer Research 31 (2): 425-40.

Inness, S. A. 2006. Secret ingredients: Race, gender and class at the dinner table. Houndmills, Basingstoke: Palgrave Macmillan.

Kozinets, R. 2001. Utopian enterprise: Articulating the meanings of Star Trek's culture of consumption. Journal of Consumer Research 28 (1): 67-88.

Lash, S., and J. Urry. 2002. Economies of signs and space. London: Sage.

Loaded. n.d.

Lury, C. 1993. Cultural rights: Technology, legality and personality. London: Routledge.

- 2004. Brands: The logos of the global economy. London: Routledge.

Manovich, L. 2001. The language of new media. Cambridge: MIT Press.

Marx, K. 1981. Economic and philosophic manuscripts of 1844. London: Lawrence \& Wishart.

Miller, D. 1987. Material culture and mass consumption. Oxford: Basil Blackwell. 1988. Appropriating the state on the council estate. Man 23: 353-72. 2005. Materiality: An introduction. In Materiality, edited by Daniel Miller. Durham: Duke University Press, $1-50$.

Mort, F. 1988. Boy's own, masculinity, style and popular culture. In Male order: Unwrapping masculinity, edited by Rowena Chapman and Jonathan Rutherford. London: Lawrence \& Wishart, 193-224.

-1996. Cultures of consumption: Masculinities and social space in late twentieth-century Britain. London: Routledge.

Murcott, A. 1983. It's a pleasure to cook for him: Food, mealtimes and gender in some South Wales households. In The public and the private, edited by Eva Gamarnikow, David Morgan, June Purvis, and Daphne Taylorson. London: Heinemann, 78-90.

. 1984. The sociology of food and eating. Aldershot: Gower Press. 
Neuhaus, J. 1999. The way to a man's heart: Gender roles, domestic ideology, and cookbooks in the 1950s. Journal of Social History 32 (3): 529-55.

Novero, C. 2000. Stories of food: Recipes of modernity, recipes of tradition in Weimar Germany. Journal of Popular Culture 34 (3): 163-81.

Oakley, A. 1974. The sociology of housework. Bath: Martin Robertson.

Oliver, J. 2000. Return of the naked chef. London: Penguin Books.

Ostberg, J., and J. Borgerson. 2004. Living la dolce vita: Embodied figurative tropes among the Stockholm brat enclave. Proceedings of the 7th ACR conference on Gender, Marketing and Consumer Behavior, Madison, Wisconsin.

O'Sullivan, J., and A. Sheridan. 2005. The king is dead, long live the king: Tall tales of new men and new management in The Bill. Gender, Work and Organization 12 (4): 299-318.

Patterson, M., and R. Elliott. 2002. Negotiating masculinities: Advertising and the inversion of the male gaze. Consumption, Markets and Culture 5: 231-46.

Pettinger, L. 2004. Brand culture and branded workers: Service work and aesthetic labour in fashion retail. Consumption, Markets and Culture 2 (June): 165-84.

Pilchner, J. 1995. Voices in the kitchen: Mexican cookbooks as cultural capital. Studies in Latin American Popular Culture 14: 297-304.

Rutherford, J. 1988. Who's that man. In Male order: Unwrapping masculinity, edited by Rowena Chapman and Jonathan Rutherford. London: Lawrence Wishart, 21-67. - 1992. Men's silences: Predicaments of masculinity. London: Routledge.

Schouten, J. W., and J. H. McAlexander. 1995. Subcultures of consumption: An ethnography of the new bikers. Journal of Consumer Research 22 (1): 43-61.

Schroeder, J. E. 2002. Visual consumption. London: Routledge.

- 2006. Masculinity, images and brand culture. Proceedings of the 8th ACR conference on Gender, Marketing and Consumer Behavior, Edinburgh, Scotland.

Schroeder, J. E., and J. L. Borgerson. 1998. Marketing images of gender: A visual analysis. Consumption, Markets and Culture 2 (2): 105-231.

Schroeder, J. E., and D. Zwick. 2004. Mirrors of masculinity: Representation and identity in advertising images. Consumption, Markets and Culture 7 (1): 21-52.

Scott, L. 1994. Images in advertising: The need for a theory of visual rhetoric. Journal of Consumer Research 21 (September): 252-73.

- 2005. Fresh lipstick: Redressing fashion and feminism. London: Palgrave Macmillan.

Seidler, V. 1987. Reason, desire and male sexuality. In The cultural construction of sexuality, edited by Pat Caplan. London: Tavistock, 46-62.

Stern, B., and J. Schroeder. 1994. Interpretive methodology from art and literary criticism: A Humanistic approach to advertising imagery. European Journal of Marketing 28: 114-32.

Tobias, S. M. 1998. Early American cookbooks as cultural artifacts. Papers on Language and Literature 34 (1): 3-18.

Trotta, J. 2004. Fighting masculinity: Stereotyping as a signifying practice in "Fight Club". Moderna Sprak 98 (2): 134-47.

Warde, A. 1994. Changing vocabularies of taste, 1967-92: Discourses about food preparation. British Food Journal 96 (9): 22-25.

Weber, M. 1979. The Protestant ethic and the spirit of capitalism. London: Unwin.

Wilk, R. 2006. Home Cooking in the Global Villages: Caribbean Food from Buccaneers to Ecotourists. Oxford: Berg.

Wright, C. 2004. Material and memory: Photography in the western Solomon Islands. Journal of Material Culture 9 (1): 73-85.

Zafar, R. 1999. The signifying dish: Autobiography and history in two black women's cookbooks. Feminist Studies 25 (2): 449-69. 